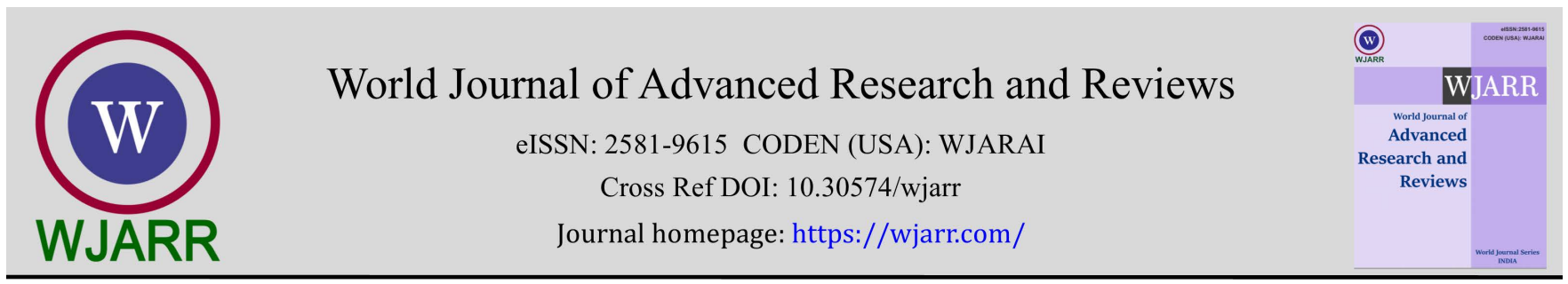

(REVIEW ARTICLE)

\title{
Electronic patient medical records: Agility in the management of medical-expert information in the aeronautical health boards
}

\author{
Patrícia Mesquita Vilas Boas ${ }^{1,}{ }^{*}$, Adriana Geórgia Davim Bastos ${ }^{2}$ and Walter Kischinhevsky ${ }^{3}$ \\ ${ }^{1}$ Public Health from the University of Fortaleza, Brazilian Air Force (FAB), Fortaleza, Ceará, Brazil. \\ ${ }^{2}$ Aeronautical Aerospace Medicine Center, Brazilian Air Force (FAB). Rio de Janeiro, Brazil. \\ ${ }^{3}$ Aeronautics Health, Brazilian Air Force (FAB). Rio de Janeiro, Brazil.
}

World Journal of Advanced Research and Reviews, 2021, 11(03), 206-212

Publication history: Received on 09 August 2021; revised on 12 September 2021; accepted on 14 September 2021

Article DOI: https://doi.org/10.30574/wjarr.2021.11.3.0441

\begin{abstract}
The Electronic Patient Record (EPR) is already a reality in the practice of many offices, diagnostic centers and hospitals. The Federal Council of Medicine (FCM) regulated its use, through FCM Resolution $n^{\circ} 1,821 / 2007$ In the Health Boards (HB) of the COMAER, agencies responsible for doing the medical-expert examinations of the military force, the paper record is still the rule. There is no automatic sharing of information between HB. In this context, it is perceived the need for the implementation of the unified EPR for the COMAER HB, because it speeds up the sharing of medical-expert information of the military and allows the military to carry out their health inspections in different locations, not interfering in the planning of missions so peculiar to the force, saving time and costs, speeding up the release of the results and control of inspections. The research thus consists of the qualitative approach, with exploratory objective and bibliographic procedure, carried out in the Scielo and Google Scholar databases, based on the discussion in ten articles, in addition to the FCM Resolutions. It was noted that the perspective that EPR has direct advantages for the Institution, however, requires an abrupt cultural change to the model that is made today, to provide a greater speed among the HB, even if in the transition phase, it is chosen to use in parallel in paper and Information and Communication Technologies. Therefore, the implementation of EPR in HB can provide both multidisciplinary teams and users of COMAER HB, a more efficient medical-expert assistance by promoting information sharing and agility in the performance of Health Inspections.
\end{abstract}

Keywords: Electronic Patient Record; Health Board; Health Information System

\section{Introduction}

Currently, in the globalized and computerized world, information is shared very quickly. Several areas of knowledge have followed the trend of globalization and adapted to the virtual world. The Electronic Patient Record (EPR) is already a reality in practice in many offices, diagnostic centers and hospitals. The Federal Council of Medicine (FCM) regulated its use, through FCM Resolution N 1,821/2007 [1]. These computerization processes require cultural changes and aim to facilitate the management of health services, information sharing in care networks, communication and, above all, improve the quality of care provided to citizens [2].

The first EPR dates to the 1970s and comes from the United States of America. In Brazil, the first models of EPR emerged in the 1990s [3]. Report that in health this advance occurred with the use of Information and Communication Technologies (ICT) [2]. Aiming to standardize the registration of all information about the patient, the FCM published Resolution N 1638/2002, which defines the medical records and makes it mandatory to create the Commission for the Review of Medical Records in health institutions [4]. It was in 2007, through Resolution N 1821/2007, that the FCM

\footnotetext{
* Corresponding author: Patrícia Mesquita Vilas Boas

Public Health from the University of Fortaleza, Brazilian Air Force (FAB), Fortaleza, Ceará, Brazil.
} 
approved the technical standards for digitization and the use of computerized systems for the custody and handling of patients' medical records, authorizing the elimination of paper and the exchange of information identified in health [1].

Under the Aeronautics Command (COMAER), it is known that there are 24 Health Boards (HB) distributed in 16 states. These HB are responsible for performing the medical-expert examinations of the military, also called "Health Inspection", according to the various purposes broken down by the Aeronautical Command System Standard (NSCA) 160-9/2021 [5]. Today in the COMAER HB, paper records are still the rule. There is no automatic sharing of information, that is, in the routine of the HB there is a great difficulty to share the health information of the military of the force. Thus, considering this problem, this academic essay argues that the implementation of EPR is an alternative so that medicalexpert information can be shared among the HB quickly, both for the benefit of the military and the institution, besides enabling the realization of the Health Inspection in different locations. In this context, the implementation of the unified EPR for the HB speeds up the sharing of medical-expert information of the COMAER military.

The health of the Aeronautics does not yet have a computerized health management system. It is urgent to implement it both in the care and expertise.

Given the difficulties in sharing information, when using the paper records, and the increasing advance in the tools for the use of electronic medical records, it is perceived the need to implement the EPR in the COMAER HB. Due to the complexity of managing information about patients in a hospital and multidisciplinary environment, it is necessary to use technology and information systems specific to the health area [6].

Experience shows that the implementation of a secure and certified electronic medical record system, which is shared among COMAER HB, with readily available, updated and structured data, enables multidisciplinary teams of the HB to better manage the information, to support, expedite and share their opinions and judgments.

There are numerous advantages of an electronic medical record, being possible to mention: agility in access to information, exchange of information, integration with other information systems, simultaneous use by various services and multidisciplinary team, elimination in the redundancy of data and requests for examination, space savings, reduction of consumption of printed materials, increased time for professionals to devote to patients, more rapidly available results, ease of data collection for reporting, readable data and correct information, no risk of loss of the files, the stored data have more legality, accuracy, and information organized more systematically, continuous processing of the data, possibility to ensure confidentiality, long-term cost reduction, safer than paper records, automatic information sharing, remote access, alert systems, structured patient history, data recovery, better quality of user care, control of the flow of patients in health services, possibility of standardizing processes, facilitates clinical research, facilitates compliance with clinical and care protocols, use of information for other purposes such as epidemiological, statistical and administrative [2-3, 7-11].

Thus, it is noted that through an integrated and computerized system, the management of health inspections by the controlling bodies becomes more efficient and organized. Every health history of the military is recorded, allowing its recovery quickly and accurately. Reports and opinions can be prepared with a greater wealth of information and more quickly. Diagnostic tests performed are available for analysis. That the Electronic Medical Record [...] "enables communication between the members of the multidisciplinary team and the continuity of the care provided to the patient" [3:124].

Thus, the agility in sharing the opinions and judgments of health inspections, as well as the medical history of the inspected, through EPR, makes the management of HB much more efficient and organized, improving the quality of assistance provided to the military of the barracks.

Discussing, still about the implementation of EPR, another positive aspect is observed in its implementation, which is the possibility of conducting health inspections of military personnel in different locations. This flexibility is important because it does not interfere in the planning of missions so peculiar to the force, saving time and costs, speeding up the release of results and control of inspections. Point out that electronic medical records facilitate intercommunication between health services, avoiding the fragmentation of information [8]. Corroborating the authors mention that EPR emerged to aggregate all patient information, contributing to the ease of access, besides being able to be accessed from any place of the institution [11].

Our country has continental dimensions, and the Air Force has a diversity of missions and military organizations (M0) spread throughout the country. Often, the military is serving in other units, performing military maneuvers or even in the process of transferring to another city. The Health Inspection should not be a limiting factor to the exercises of these 
activities, but in fact it is, for example, a military linked to an Aeronautical Health Organization (AHO), to make a Health Inspection outside its locality, faces great difficulty to be inspected, just see that for this to occur it is necessary an inspection order and not to mention that the locality will not have access to its medical-expert history. Therefore, you will be required to do a full Health Inspection, which generates much more cost and time, since many units do not have all the medical arsenal and diagnostics necessary to carry out the Health Inspection in the short term or within the period in which the military is displaced from its MO.

In addition, another illustration would be a request for a Health Inspection by an AHO, located in the northern region of Brazil, to the Center for Aerospace Medicine (CEMAL), located in Rio de Janeiro (RJ). For this inspection to take place it is necessary to send a letter for scheduling the inspection, forward the military to the city of Rio de Janeiro, and forward a medical report and copy of all his medical records. Sending this data can be time consuming and sometimes insufficient. In addition to generating costs, sometimes unavailable. If the EPR was already implemented, the scheduling could be done online and it would only be necessary the military to come, given that all your health information would be available for the health inspection.

In this follow-up, it is contact that the implementation of EPR inhibits the fragmentation of information and facilitates access to the military's medical history, enabling a better dynamic in health inspections, much more flexible, safe and efficient. In addition, it saves on costs and time, aspects that greatly benefit the military organizations of COMAER.

\section{Methods}

To better understand the study, qualitative research was defined as a method of approach. It is attributed that this research method allows for the research, a higher understanding of the importance of electronic medical records, since it works on a hypothetical and suggestive question. Thus, we seek to delineate the understanding and understanding of the advantages and disadvantages of the use of this system for health boards.

In fact, this study approach focuses on demonstrating, describing, understanding, not by numerical means, restrictive, but provides to observe both locally and globally, the effects found in the bibliographic survey.

Thus, the purpose of the objectives established by the study is based on the exploratory method that is, as described to foster an understanding of the problem presented in the introduction of the research, allowing a construction of hypothesis or make the problem more evident [12]. As the understanding of EPR advances, it is possible to understand together all the systematics that have not made it operational yet, seeking to understand possible limitations for the implementation.

In this, it is presented that the procedure of searching for the data analyzed in the study is based on the premise of the bibliographic method. This type of research is dedicated to support, to provide a theoretical discussion, a set of previous sources of authors who have already dedicated themselves on the subject, so that it can create an argumentative survey to obtain the results studied. It is listed that the investigations obtained by this study procedure allow us to be in different positions about a given problem [13].

\section{Results}

With the purpose of developing the theme, the research began with the collection of data in certain databases, such as: Google Scholar and Scielo, as well as in the Ordinances of the Federal Council of Medicine and pages of the Federal Government.

The initial purpose of the search was to try to draw a parallel between the understanding in Civil Society and the Military Unit, since no support was found on the subject in the military aspect only, at least in the Brazilian case, since it is specific research in territory.

For this, some descriptors were used, among them: Medical Records, Information Systems, Electronic Medical Records, Hospital Information Systems and Medical Informatics. Based on the descriptors, some criteria were used for the selection of materials returned in the search, and some exclusion criteria were adopted, among which: research with more than 10 years; research outside the vernacular language and works not contemplated by peers. 
The research in both databases returned 103 results, among which 62 were excluded after reading title and abstracts. In the next stage, about 31 articles did not fully cover the stipulated criteria, leaving 10 for the full reading of the research, as shown in Figure 1.

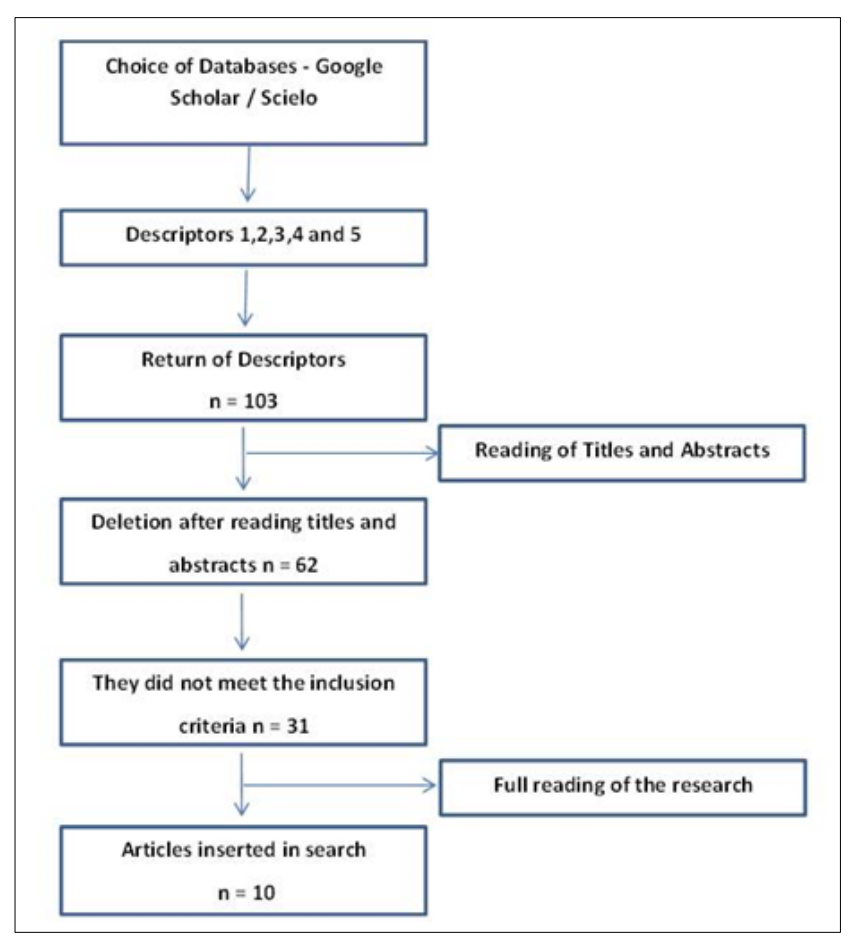

Figure 1 Procedure for obtaining search results

It is possible to note, from the figure presented, that the present study permeates through these ten texts, however, which will allow a deeper understanding during the discussion phase. Here, however, the legislative and normative texts were not included, and only scientific, non-documentary research was strict.

\section{Discussion}

Understanding the issue of globalization and military necessity is central to the discussion of research, especially when considering the issue of the territorial dimension of Brazil. Therefore, the focus is not only on the issue of the role per se, as an agent in a globalized environment with technological advancement, but also the focus is on the speed of the process that EPR can provide.

Thus, the main issue lies in the institution's own culture [2]. Nevertheless, the FCM, through its Resolution N 1,821/2007 [1], intensifies the importance of EPR, corroborating the external theory already consolidated in the United States. However, it is necessary to consider that mentions there are also limitations in the use of EPR, such as resistance on the part of professionals, need for training and financial investments [14].

Thus, it is not possible to establish only a few criteria, as endowed in Civil Society for the COMAER HB, since all the detail needs a much greater accuracy to not corrupt the available data. Thus, based on the conception of the FCM for EPR, it is still not enough to establish an integral relationship between military institution and civil society, since this distinction is clear and must meet different criteria. Perhaps, therefore, there is still resistance in the implementation of this system, regarding the medical-forensic examinations of the military.

The FCM considerations, thus, can provide the basis for the standards of digitization, use of systems, handling and storage of the medical records of patients [3]. But, turning to the argumentative transfer of military personnel to other bases, it is possible to highlight the issue of speed, space saving and better management of contingent information by the Ministry and / or government authorities [11].

This is what will point out in the experience of converting the paper records to the electronic medical records adopted by the Brazilian Army [15]. However, the author admits that even if considered by many as obsolete, paper files have 
great reliability, since they are subject only to destruction by fires, loss, humidity and the like. The understanding here is not erroneous when observed in the question of the difficulty of implementation and the disadvantage listed [11,14].

Another point in consideration is that many institutions, because they contain sensitive information from their boards tend not to opt for "cloud" storage [15]. The question, therefore, is taken at a higher level than just the idea of formulating an electronic medical record, but the sharing among the $24 \mathrm{HB}$ spread throughout Brazil. As found during the research, the centralized model of the institution itself makes it too difficult to access this information, which brings slowness to the process.

That multidisciplinarity is central in the management of patient information since it is not only the issue of computerization or the use of technology [6]. It is essential that a continuous and complete feeding for the available data does not lack information. It is suggested the possibility, from the experience of the Australian EPR, that the patient can follow the situation of his medical records [16]. That is, instead of the professional requesting a certain examination, already performed in another HB or by another professional and not included in the medical records, generating onerosity and waste in the discovery of information, it would be possible through EPR to mitigate such failure.

In the specific question of medical expertise, that cites the increase in the efficiency of clinical processes, reduction of medical errors, in the case of experts and an improvement in the quality of patient care [6]. Nevertheless, the complete information, present within the EPR, when properly inserted, can facilitate health professionals to make a correct decision [17].

On this question "Another major problem generated by the informational inefficiency of the Australian health system is the psychological pressure on the health workforce, as health professionals often need to make diagnostic and treatment decisions with incomplete information. On the other hand, patients have a limited participation in decisions about their health, because they do not have access to all the information that was recorded, at different times, by different health professionals" [16:142].

Nevertheless, what is proclaimed, is that many institutions can maintain a paper route in parallel with the EPR system, without there being a real need $[7,15]$. It is perceived that the question turns, in view of the structural technological limitation, but not only. When conducting a research with students, nurses and physicians to list the advantages and disadvantages of EPR, presented three main reservations on their part, namely: System "off the air"; Need for Training and; secrecy [11].

However, deal with the theme in the aspect of the usability of the system by users, that is, in addition to demanding a high investment, especially when talking about the availability of data for the $24 \mathrm{HB}$ scattered throughout the country, the issue is related to the adaptability of professionals [9]. Therefore, it is not only the training itself, but all the cultural transformation necessary for the system and the demands for its creation. It is necessary for the institution to create strategies and indirect costs linked to the system.

Also present observances in this regard, especially in the specific treatment between information technology professionals and multidisciplinary users who will have access to this system [6]. It is necessary that they move synergistically, so that the effectiveness of decisions is assertive and accurate, generating the lowest onerosity and expenditure on the part of professionals and patients.

Independent, EPR, in short, should be a secret system, of ethical-legal and scientific character, with assistencialists' vision [3]. The objective of EPR is to provide a greater possibility of understanding on the part of the health professional and not dehumanization. This is because the professional with all the necessary data, in electronic environment, can devote himself to the patient more fully [11].

Taking care of the scenario studied, it is possible to portray that the Health Inspection will generate less cost and time, causing the military not to move outside the period or in a short period of its military organization in operation. Therefore, it will be possible that the documentation of the medical records for a given examination is available when filling out data access to the system. The focus of EPR is strictly to eliminate redundancies from the paper records, providing a systematic organization $[9,17]$.

It is denoted that EPR integrates management and assistance in a way that both act in favor of the authenticity and unity of data, causing possible inconsistencies of military data to be dissipated, which would mitigate the loss of resources. Provides that for the Institution not to need to develop a new system from "zero", it is possible that it uses one already tested in Federal Hospitals or by other Singular Forces, making the implementation more rational and safer [15]. 


\section{Conclusion}

The COMAER Health Boards are responsible for performing the medical-expert examinations of the military force, in accordance with the health laws of the Air Force. The patient's medical record is the work tool of the HB, and the paper records are the rule. This type of medical records does not allow integration between the HB, which are spread in several units of the federation. Therefore, it is advocated that the implementation of the unified EPR for the HB speeds up the sharing of medical-expert information of the COMAER military.

The computerization of the HB, through the implementation of the unified EPR, speeds up the sharing of medical-expert information of the military and enables the military to carry out their health inspections in different locations, saving time and costs, speeding up the release of results and control of health inspections.

Moreover, it is observed the various advantages presented by the scientific community regarding the implementation of EPR, corroborating the idea that the implementation of a computerized system to manage the COMAER Health Boards, enables a better management of health inspections.

In a statement, it reinforces the idea that EPR implementation can provide both multidisciplinary teams and COMAER HB users, a more efficient medical-expert assistance by promoting information sharing and agility in conducting health inspections. It is emphasized the need for studies that enable the creation of a computerized system, which can be implemented in the COMAER HB, according to current legislation.

\section{Compliance with ethical standards}

\section{Acknowledgments}

We thank all who participated in the study.

\section{Disclosure of conflict of interest}

The authors declare that there is no conflict of interest.

\section{References}

[1] Brasil. Resolução CFM n 1.821, de 23 de novembro de 2007. Aprova as normas técnicas concernentes à digitalização e o uso dos sistemas informatizados para a guarda e manuseio dos documentos dos prontuários dos pacientes, autorizando a eliminação do papel e a troca de informações identificada em saúde. Diário Oficial da União, Brasília, Seção I. 2007; 252, 23.

[2] Pereira FN, Almario A, Soares C, Souza ARL, Uzam CPP. Prontuário Eletrônico do Paciente (PEP) sua aplicabilidade e contribuição como instrumento de integração segura da informação nas redes de atendimento à saúde. Rev Universidade Ibirapuera. 2017; 14: 18-26.

[3] Patrício CM, Maia MM, Machiavelli JL, Navaes MA. O Prontuário Eletrônico do Paciente no Sistema de Saúde Brasileiro: uma realidade para os médicos? Sci Med. 2011; 21(3): 121-31.

[4] Brasil. Conselho Federal de Medicina. Resolução CFM nº 1.638 de 09 de agosto de 2002. Define prontuário médico e torna obrigatória a criação da Comissão de Revisão de Prontuários nas instituições de saúde. Diário Oficial da União, Brasília, Seção I, 184-5, 09 ago. 2002.

[5] Brasil. Comando da Aeronáutica. Comando-Geral do Pessoal. Portaria COMGEP n 115/ALE, de 11 de janeiro de. Aprova a reedição da Norma de Sistema que dispõe sobre as "Inspeções de Saúde no Comando da Aeronáutica" (NSCA 160-9). Boletim do Comando da Aeronáutica. 2021; 14069: 208.

[6] Muylder CF, Carneiro SD, Barros LC, Oliveira JG. Prontuário Eletrônico do Paciente: aceitação de tecnologia por profissionais da saúde da região metropolitana de Belo Horizonte. Rev Adm Inov Hosp. 2017; 14(1): 1-13.

[7] Conselho Federal de Medicina. Sociedade Brasileira de Informática em Saúde. Cartilha sobre Prontuário Eletrônico - A Certificação de Sistemas de Registro. Brasília: CFM/SBIS. 2012.

[8] Gonçalves JPP, Batista LR, Carvalho LM, Oliveira MP, Moreira KS, Leite MTS. Prontuário Eletrônico: uma ferramenta que pode contribuir para a integração das Redes de Atenção à Saúde. Saúde Debate. 2013; 37(96): 43-50. 
[9] Jenal S, Évora YDM. Desafio na Implantação de prontuário eletrônico do paciente. J Health Inf. 2012; 4(n. esp.): 216-9.

[10] Jenal S, Évora YDM. Revisão de literatura: Implantação de prontuário eletrônico do paciente. J Health Inf. 2012; 4(4): 176-81.

[11] Martins C, Lima SM. Vantagens e desvantagens do prontuário eletrônico para instituição de Saúde. Rev Adm Saúde. 2014; 16(63): 61-6.

[12] Gil AC. Como elaborar Projetos de pesquisa. São Paulo: Atlas. 2007.

[13] Oliveira MM. Como Fazer: Projetos, Relatórios, Monografias, Dissertações e Teses. Rio de Janeiro: Campus. 2011.

[14] Moraes JC, Araújo AAC, Cavalcanti PN, Leite WM, Madeira MZA. Prontuário eletrônico do Paciente: vantagens e limitações. Anais do I Congresso Norte-Nordeste de Tecnologias em Saúde. 2017; 1(1).[15] Grasselli EA. Implantação do Sistema de Informações Hospitalares do Exército Brasileiro: do prontuário de papel ao prontuário eletrônico [Trabalho de Conclusão]. Rio de Janeiro (RJ): Escola de Saúde do Exército. Exército Brasileiro: Ministério da Defesa. 2019.

[15] Galvão MCB, Ricarte ILM. O prontuário eletrônico do paciente em escala nacional: o caso australiano. InCID: R Ci Inf e Doc. 2019; 10(1): 244-64.

[16] Cavalcante FP, Magnagnagno OA. O impacto do armazenamento eletrônico de dados no atendimento clínico hospitalar. Rev Thê Sci. 2019; 9(2): 58-67. 